\title{
ZD6 126 inhibits orthotopic growth and peritoneal carcinomatosis in a mouse model of human gastric cancer
}

\author{
MF McCarty', A Takeda ${ }^{2}$, O Stoeltzing', W Liu², F Fan², N Reinmuth², M Akagi', C Bucana' ${ }^{2}$ PF Mansfield', \\ A Ryan ${ }^{3}$ and LM Ellis*,I \\ 'Department of Surgical Oncology, The University of Texas MD Anderson Cancer Center, 1515 Holcombe Blvd., Box 444, Houston, TX 77030-4009, \\ USA; ${ }^{2}$ Department of Cancer Biology, The University of Texas MD Anderson Cancer Center, 1515 Holcombe Blvd., Box 444, Houston, TX 77030-4009, \\ USA; ${ }^{3}$ Cancer and Infection Bioscience Department, AstraZeneca, Macclesfield, UK
}

\begin{abstract}
The purpose of this study was to examine the effects of ZD6126, a novel vascular-targeting agent, on tumour growth and angiogenesis in an orthotopic model of gastric cancer. TMK-I human gastric adenocarcinoma cells were injected into the gastric wall of nude mice. After the tumours were established (day 14), therapy was initiated. Mice $(n=1 \mid-12 /$ group) received (a) vehicle, (b) ZD6126 at $100 \mathrm{mg} \mathrm{kg} \mathrm{day}^{-1}$ i.p. one time per week or (c) ZD6126 at $100 \mathrm{mg} \mathrm{kg} \mathrm{day}^{-1}$ i.p. five times per week. Tumour mass, volume and the presence or absence of peritoneal carcinomatosis were determined at sacrifice on day 38 . Tumours from each group were stained for markers of blood vessels, proliferation and apoptosis. To further define the time frame of the vascular-targeting effects of chronic therapy with ZD6 I26, TMK-I cells were again injected into the gastric wall of mice in a second experiment. On day 14, a single i.p. injection of ZD6126 $100 \mathrm{mg} \mathrm{kg}^{-1}$ mouse ${ }^{-1}$ or vehicle was delivered. Groups of three mice each were killed and the tumours harvested at days I, 3 and 5 post-ZD6126 injection. Tumours were processed and stained for endothelial and tumour cell apoptosis and proliferation. No overt toxicity was observed with ZD6I26 therapy. ZD6I26 led to a marked inhibition of tumour growth $(82 \%$ decrease vs control $(P<0.00 I))$. ZD6 I 26 also led to a significant decrease in the incidence of peritoneal carcinomatosis ( I 0 out of I 2 controls, vs one out of I 2 ZD6 I 26) ( $P<0.0$ I). Histological analysis of tumours revealed large regions of central necrosis in the treated group, as well as a dramatic increase in tumour cell apoptosis $(7.4$-fold increase $(P<0.00 \mathrm{I})$ ), consistent with the vascular-targeting activity of ZD6 126. Mice treated with ZD6126 demonstrated a 59\% decrease in PCNA-positive cells $(P<0.02)$, indicating reduced tumour cell proliferation. In addition, tumours treated with ZD6126 exhibited a 40\% decrease in microvessel density $(P<0.05)$. Results from mice treated with a single injection of ZD6 26 demonstrated the acute effects this agent has on the tumour vasculature. The ratio of endothelial cell apoptosis to endothelial cell proliferation was increased within $24 \mathrm{~h}$ of a single injection. In conclusion, ZD6126 significantly inhibited tumour growth and metastasis in an orthotopic model of human gastric adenocarcinoma, without detectable problematic adverse effects. These data suggest that ZD6 126 may be worthy of investigation in
\end{abstract} the treatment of primary gastric adenocarcinoma.

British Journal of Cancer (2004) 90, 705-7II. doi:10.1038/sj.bjc.6601490 www.bjcancer.com

(c) 2004 Cancer Research UK

Keywords: endothelium; apoptosis; neovascularisation inhibitors; neoplasm metastasis

The 5-year survival rate for patients with gastric cancer in the United States is only 5-15\% (Karpeh et al, 2001). The mortality associated with gastric cancer has remained relatively stable over the past 20 years, suggesting that new therapies to combat this problem are urgently needed (Karpeh et al, 2001). Recent studies have shown that targeting the tumour vasculature may be of therapeutic benefit in gastric cancer (Mori et al, 2000; Yoshikawa et al, 2000; Jung et al, 2002; Kamiyama et al, 2002).

The generation and maintenance of a functional vasculature is necessary for tumours to increase in size beyond $1-2 \mathrm{~mm}$ (Folkman, 1992). Anti-angiogenic agents target biological pro-

\footnotetext{
*Correspondence: LM Ellis; E-mail: lellis@mdanderson.org

These studies were supported, in part, by NIH Cancer Center Support Grant CA 16672, the Carlos Cantu Foundation (PFM) and a grant from AstraZeneca (LME)

Received 6 June 2003; revised 15 October 2003; accepted 22 October 2003
}

cesses involved in the generation of new blood vessels, for example, by blocking the receptor-ligand systems important for the angiogenic response (Bruns et al, 2000; Jung et al, 2002). However, by the time the cancer is diagnosed, most tumours already have an intact, functional vascular network (Folkman, 1992). Significantly, tumour vasculature seems to be fundamentally different from normal vasculature (Denekamp, 1990). For example, tumour endothelium is characterised by tortuous, leaky vessels with chaotic blood flow (Fukumura et al, 1997) and a significant proportion of immature, proliferating endothelial cells, which is in contrast to the ordered vessels and quiescent endothelial cells found in normal tissues (Skinner et al, 1995; Brown and Giaccia, 1998). Targeting the phenotypic differences between tumour vasculature and normal vasculature is particularly attractive because it has the potential to be effective against established tumours, which are often considered to be resistant to standard chemotherapeutic approaches.

In contrast to anti-angiogenic therapies, vascular targeting therapies aim to selectively and irreversibly disrupt tumour blood 
flow, inducing prolonged ischaemia and subsequent secondary necrotic tumour cell death (Reviewed in (Chaplin and Hill, 2002). A wide range of potentially effective vascular-targeting approaches has been described, each exploiting distinctive features of the tumour vasculature (Denekamp, 1990; Bloemendal et al, 1999; Thorpe et al, 2003). Vascular-targeting activity is a common feature of tubulin-binding microtubule destabilising agents such as colchicines and vinca alkaloids. Although these agents have significant vascular-targeting activity in animal tumour models (Chaplin et al, 1996) this is only seen at or around their maximum tolerated dose (MTD). More than half a century ago, colchicine, one of the oldest known tubulin-binding agents, was found to cause extensive central necrosis and hemorrhage of tumours when administered to cancer patients, presumably through vasculartargeting activity (Seed et al, 1940). However significant toxicity prevented its further clinical development as an anti-cancer agent. Therefore, newer agents that more selectively disrupt tumour vasculature with a wider therapeutic margin over normal tissue effects have been sought for clinical evaluation. In particular, two compounds currently in phase II clinical development (combretastatin A-4 phosphate and ZD6126) have demonstrated selective effects on tumour vasculature in animal models at doses significantly below their MTD (Dark et al, 1997; Davis et al, 2002). Although the molecular mechanisms underlying the vascular-targeting activity of these agents is not well understood, a range of in vitro endothelial cell responses (eg cytoskeletal reorganisation, cell shape change) and in vivo vascular responses (eg vascular collapse, increased permeability, decreased perfusion) have been described that could play a significant role in their antitumour effects (Griggs et al, 2001; Blakey et al, 2002; Davis et al, 2002).

ZD6126, is a novel vascular-targeting agent that was developed for its ability to bind tubulin and induce vascular damage in tumours (Davis et al, 2002). It has a wide therapeutic index in mouse tumour models producing selective antivascular effects in tumours at doses ranging from $1 / 8$ th to $1 / 16$ th of the MTD in mice (Davis et al, 2000; Blakey et al, 2002; Siemann and Rojiani, 2002). ZD6126 has significant antitumour effects in a wide range of histologically distinct subcutaneous tumour xenografts in nude mice (Blakey et al, 2002). However, the efficacy of ZD6126 has not been examined at orthotopic sites where the endothelia are phenotypically distinct and tumour growth is likely to be more physiologically relevant to human disease (Craig et al, 1998; Chi et al, 2003).

The aim of this study was to determine the efficacy of singleagent ZD6126 therapy on tumour growth and vasculature in an orthotopic model of gastric cancer.

\section{MATERIALS AND METHODS}

\section{Cell culture}

TMK-1, a poorly differentiated human gastric adenocarcinoma cell line, was a generous gift of Dr Eiichi Tahara (Hiroshima University, Hiroshima, Japan), and was cultured and maintained in Dulbecco's modified Eagle medium supplemented with $10 \%$ fetal bovine serum, as described previously (Jung et al, 2002).

\section{Formulation of ZD6126}

ZD6126, a phosphate prodrug of $\mathrm{N}$-acetylcolchinol, was provided by AstraZeneca (Macclesfield, England). ZD6126 was dissolved in $5 \%$ sodium carbonate and diluted to the final volume with phosphate-buffered saline (PBS), as previously described (Blakey et al, 2002). Solutions were sterilised by filtration through a 0.22 $\mu \mathrm{m}$ filter and stored at $4^{\circ} \mathrm{C}$.

\section{Animal studies}

Male athymic mice, 8-week old (obtained from the National Cancer Institute Animal Production Area, Frederick, MD, USA), were acclimated for 1 week and caged in groups of five. All animal studies were conducted under the guidelines approved by the Animal Care and Use Committee of The University of Texas MD Anderson Cancer Center, and met all of the standards required by the UKCCCR guidelines for the welfare of animals in experimental neoplasia, as published (Workman et al, 1998).

Mice were anaesthetised by i.p. injection of sodium phenobarbital (Nembutal, $50 \mathrm{mg} \mathrm{kg}^{-1}$ ) and, under sterile conditions, subjected to an upper midline laparotomy. TMK-1 cells $\left(10^{6}\right)$ in Hank's balanced salt solution were injected into the wall of the mid-stomach. After 14 days, when tumours were approximately 1 $2 \mathrm{~mm}$ in diameter, mice were randomly assigned to one of three groups: (a) daily-dose control (PBS $+5 \%$ sodium carbonate, $\mathrm{pH}$ 7.0, $n=12)$; (b) weekly-dose ZD6126 (100 mg kg ${ }^{-1}, 1$ day week $\left.^{-1}\right)$; and (c) daily-dose ZD6126 (100 mg kg ${ }^{-1}, 5$ days week $\left.{ }^{-1}, n=11\right)$ (Figure 1). The weekly dose group received four injections of ZD6126 on days 14, 21, 28 and 35, and received the last injection 3 days prior to sacrifice. The daily dose group received 18 injections (days $14-18,21-25,28-32,35-37$ ) and received the last injection $24 \mathrm{~h}$ prior to sacrifice. Body weight at randomisation was similar among groups and animals in all groups gained weight at a similar rate throughout the experiment. Since this tumour model can result in animals rapidly becoming moribund from bowel obstruction, mice were very closely monitored for signs of loss of clinical condition associated with morbidity. In this experiment, all mice were euthanised by $\mathrm{CO}_{2}$ asphyxiation on day 38 when $25 \%$ of the control mice showed clinical signs (lack of activity and increase tumour burden on palpation), indicating that they would be expected shortly to become moribund. Body weights were measured, tumours were excised, tumour weight and diameters were subsequently determined and the presence or absence of peritoneal carcinomatosis was noted. Tumour volumes were calculated by the equation width ${ }^{2} \times$ length $\times 0.5$. Tumour tissue was harvested and placed in either $10 \%$ buffered formalin for paraffin fixation or optimal cutting temperature (OCT) compound (Miles Inc., Elkhart, IN, USA) and frozen in liquid nitrogen for subsequent immunohistochemical analysis.

In a separate experiment to clarify the timing of the antivascular effect of ZD6126, mice bearing established orthotopic tumours were injected with a single dose of ZD6126 $\left(100 \mathrm{mg} \mathrm{kg}^{-1}\right)$ or control solution (PBS $+5 \%$ sodium carbonate) 14 days after tumour-cell implantation. These mice were injected i.p. with $1 \mathrm{mg} /$ $0.2 \mathrm{ml}$ of 5 -bromo-2'-deoxyuridine (BrdU) (Sigma, St Louis, MO, USA) dissolved in PBS $1 \mathrm{~h}$ before euthanasia to determine the fraction of proliferating cells. Three mice per group were euthanised at days 1,3 , or 5 after a single injection of ZD6126, and the tumour tissues were harvested as above.

\section{Immunostaining of microvessels, proliferative and apoptotic cells}

Tissue sections were sectioned and stained for H\&E, CD31 (vessels), TUNEL (apoptotic cells), BrdU (proliferative cells) and PCNA (proliferative cells), as previously described (Reinmuth et al, 2002; Stoeltzing et al, 2003). All tumour tissues were counterstained either with Gill's 3 haematoxylin (Sigma; immunochistochemical analysis), or incubated with $300 \mu \mathrm{g} / \mathrm{ml}$ of Hoechst stain for 1-2 min (Sigma, immunofluorescent analysis). The antibodies used were as follows: rat anti-mouse CD31 (Pharmingen, San Diego, CA, USA), mouse anti-BrdU (Becton Dickinson, Franklin Lakes, NJ, USA), mouse anti-human PCNA PC-10 (DAKO, Carpinteria, CA, USA), DeadEnd Fluorometric TUNEL system (Promega, Madison, WI, USA), rat anti-mouse IgG $_{2 a}$ (Serotec, Raleigh, NC, USA), Texas Red goat anti-rat secondary antibody 
(Jackson Research Laboratories, West Grove, CA, USA) and goat anti-mouse IgG Alexa Fluor 488 (Molecular Probes, Eugene, OR, USA).

\section{Analysis of immunostained tissue sections}

Sections were examined using a Zeiss photomicroscope (Carl Zeiss Inc., Thornwood, NY, USA) equipped with a 3-chip chargecoupled device colour camera (DXC-960 MD; Sony Corp., Tokyo, Japan). The images were analysed using Optimas image analysis software (version 5.2; Bothell, WA, USA). Positive cells were counted using Scion software, based on the NIH Image program for Macintosh (Scion Corporation, Frederick, MD, USA). Quantification of positive cells was expressed as the average of the number of cells in $0.05-\mathrm{mm}^{2}$ high-power fields at $\times 200$. Five fields from one $8-10 \mu \mathrm{m}$ section per tumour specimen were chosen randomly and 3-5 specimens per group underwent analysis. Each field contained more than 2000 cells. Areas of obvious necrosis (as determined by either the haematoxylin or Hoechst counterstain) were avoided. The ratio of endothelial cell apoptosis to endothelial cell proliferation was determined by counting the number of CD31-positive/TUNEL-positive cells divided by the number of CD31-positive/BrdU-positive cells per high-power field.

\section{Statistical analysis}

Statistical differences among groups were examined using the twotailed Student's $t$-test, the $\chi^{2}$ test, or, for analysis of nonparametric data, the Mann-Whitney $U$-test with InStat Statistical Software (GraphPad Software, San Diego, CA, USA). The results of the in vivo experiments were tested for outliers using Grubb's test (www.graphpad.com). A $P$-value of less than 0.05 was considered statistically significant.

\section{RESULTS}

\section{Effect of ZD6126 on growth of primary gastric tumours}

No difference was discerned in the body weight or grooming habits of the treatment groups (multiple-dose ZD6126, single-dose ZD6126, or control). The effects of ZD6126 on the growth of TMK-1 cells implanted into the stomach walls of nude mice are shown in Table 1. Tumour volume was reduced in both the weeklydose group ( $45 \%$ decrease, $P<0.05)$ and the daily-dose group (82\% decrease, $P<0.002$ ) (Figure 2, Table 1). Tumour mass was less in the group given daily ZD6126 than in the control mice $(P<0.05)$, but weekly ZD6126 did not significantly reduce tumour mass relative to that in the control group $(P=0.26)$.

\section{Effect of ZD6126 on incidence of peritoneal carcinomatosis}

TMK-1 cells are known to induce peritoneal carcinomatosis in a similar mouse model (Minagawa et al, 2001). In our study, daily

Table I Treatment of gastric cancer with ZD6/26

\begin{tabular}{|c|c|c|c|}
\hline & \multirow[b]{2}{*}{ Control } & \multicolumn{2}{|c|}{ ZD61 $26\left(100 \mathrm{mg} \mathrm{kg}^{-1}\right)$} \\
\hline & & Weekly & Daily \\
\hline $\begin{array}{l}\text { Body mass }(\mathrm{g}) \pm \text { s.e.m. } \\
\text { Tumour volume }\left(\mathrm{mm}^{3}\right) \pm \text { s.e.m. } \\
\text { Tumour mass }(\mathrm{g}) \pm \text { s.e.m. } \\
\text { Incidence of carcinomatosis }\end{array}$ & $\begin{array}{c}30.9 \pm 0.8 \\
440 \pm 154 \\
0.5 \pm 0.1 \\
10 / 12(83.3 \%)\end{array}$ & $\begin{array}{c}31.3 \pm 1.0 \\
241 \pm 39^{b} \\
0.4 \pm 0.1 \\
6 / 12(50 \%)\end{array}$ & $\begin{array}{r}29.2 \pm 0.7 \\
79 \pm 25^{a} \\
0.2 \pm 0.1^{b} \\
1 / 11(9.1 \%)^{c}\end{array}$ \\
\hline
\end{tabular}

TMK-I was injected into the gastric wall on day 0. Therapy with ZD6 I26, either once a week (weekly) or $5 \times$ per week (daily), was initiated on day I4. Mice were killed on day 38 . ${ }^{a} P<0.002$ by Student's $t$-test. ${ }^{p} P<0.05$ by Student's $t$-test. ${ }^{c} P<0.0$ l by $\chi^{2}$ analysis.

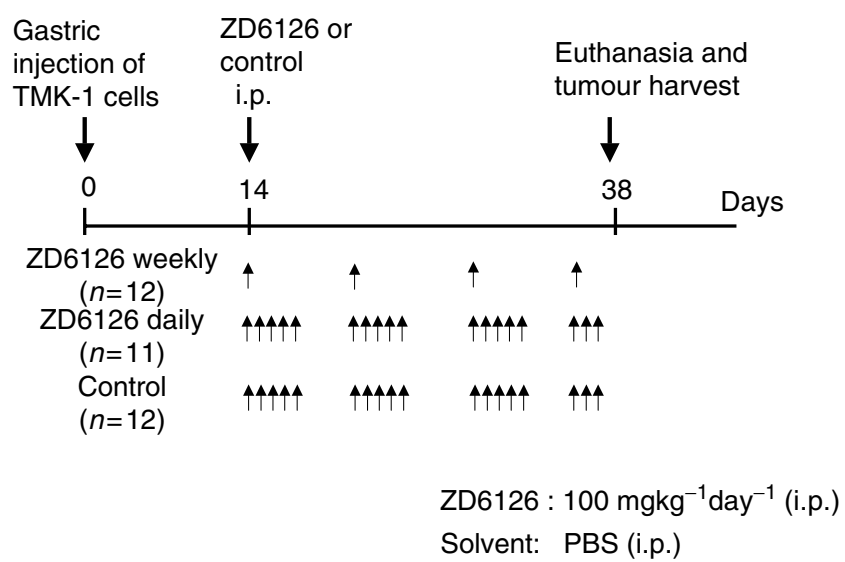

Figure I Experimental design of ZD6I26 therapy for gastric cancer growing in an orthotopic site. TMK-I human gastric cancer cells $\left(10^{6}\right)$ were injected into the gastric walls of nude mice. Mice were randomised to one of three groups: control, ZD6I26 I day week ${ }^{-1}$, or ZD6I26 5 days week $^{-1}$. Treatment with ZD6I26 $\left(100 \mathrm{mg} \mathrm{kg}^{-1}\right)$ or control began on day 14 by i.p. injection. On day 38, all mice were euthanised.
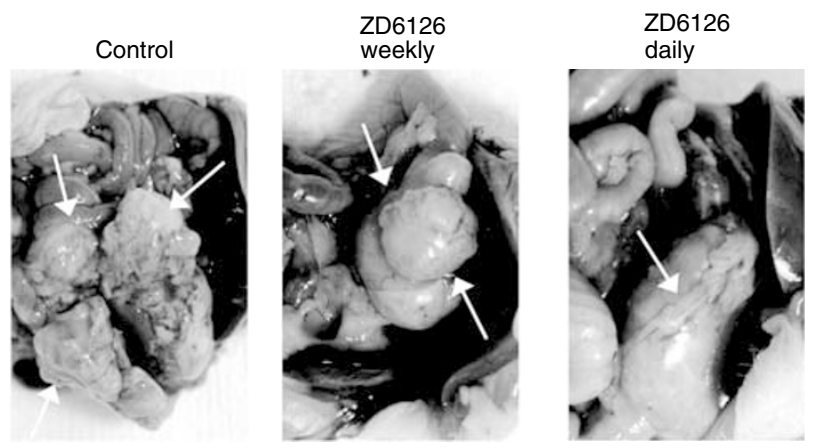

Figure 2 Effects of ZD6/26 on gastric tumour growth. TMK-I cells $\left(10^{6}\right)$ were injected into the stomach walls of nude mice, and therapy was begun on day I4. Photographs show that daily ZD6I26 administration was more effective in inhibiting tumour growth than daily administration or control.

ZD6126 therapy led to a reduction in the incidence of peritoneal deposits: $83 \%$ of the control mice developed gross peritoneal carcinomatosis, and this was reduced to less than $10 \%$ of mice treated with daily ZD6126 $(P<0.01)$ (Table 1$)$. Weekly ZD6126 did not significantly affect the development of carcinomatosis $(50 \%$ incidence, $P=0.08 v s$ controls).

\section{Decreased microvessel density in ZD6126-treated animals}

Immunohistochemical staining for CD31 to determine the microvessel density revealed no difference between the control mice and those given weekly ZD6126. However, microvessel density was reduced by $40 \%$ in mice treated daily with ZD6126 relative to that in the control group $(P<0.05)$ (Table 2, Figure 3$)$.

\section{Tumour cell proliferation and cell death in ZD6126-treated animals}

The proliferative and apoptotic rates of the tumour cells in each of the three groups are shown in Table 2 and Figure 3. Significantly fewer PCNA-positive cells were found in tumours in the ZD6126treated groups $(53 \%$ fewer in the weekly group $(P<0.01)$ and $58 \%$ fewer in the daily group $(P<0.05))$, concomitant with significant increases in TUNEL-positive cells in both groups (5.3-fold increase 
Table 2 Treatment of gastric cancer with ZD6/26

\begin{tabular}{lrrr}
\hline & & ZD6126 $\left(\mathbf{1 0 0 ~} \mathbf{~ m g ~ k g}^{-\mathbf{1}}\right)$ \\
\cline { 3 - 4 } & Control & Weekly & Daily \\
\hline Microvessel density \# of vessels/HPF & $12.0 \pm 1.5$ & $10.1 \pm 1.2$ & $7.2 \pm 1.6^{\mathrm{a}}$ \\
Proliferating cells \# of cells/HPF & $16.9 \pm 2.5$ & $8.0 \pm 1.1^{\mathrm{b}}$ & $7.0 \pm 1.3^{\mathrm{a}}$ \\
Apoptotic cells \# of cells/HPF & $2.0 \pm 0.4$ & $10.8 \pm 3.7^{\mathrm{b}}$ & $15.0 \pm 3.0^{\mathrm{c}}$ \\
\hline
\end{tabular}

TMK-I was injected into the gastric wall on day 0 . Therapy with ZD6126, either once a week (weekly) or $5 \times$ per week (daily), was initiated on day I4. Mice were killed on day 38. Tumours were harvested and tissue sections were stained with antibodie against $C D 3$ I to determine the microvessel density, PCNA to determine the cycling cells, or TUNEL to determine apoptotic cells. Measurements are the mean \pm the standard error, as determined by counting the positive cells in each of five $\times 200$ high-powered fields (HPF) for at least five tumours from each treatment or control group. ${ }^{\mathrm{a}} \mathrm{P}<0.05$. ${ }^{\mathrm{b}} \mathrm{P}<0.0 \mathrm{l}$. ${ }^{\mathrm{c}} \mathrm{P}<0.00 \mathrm{l}$
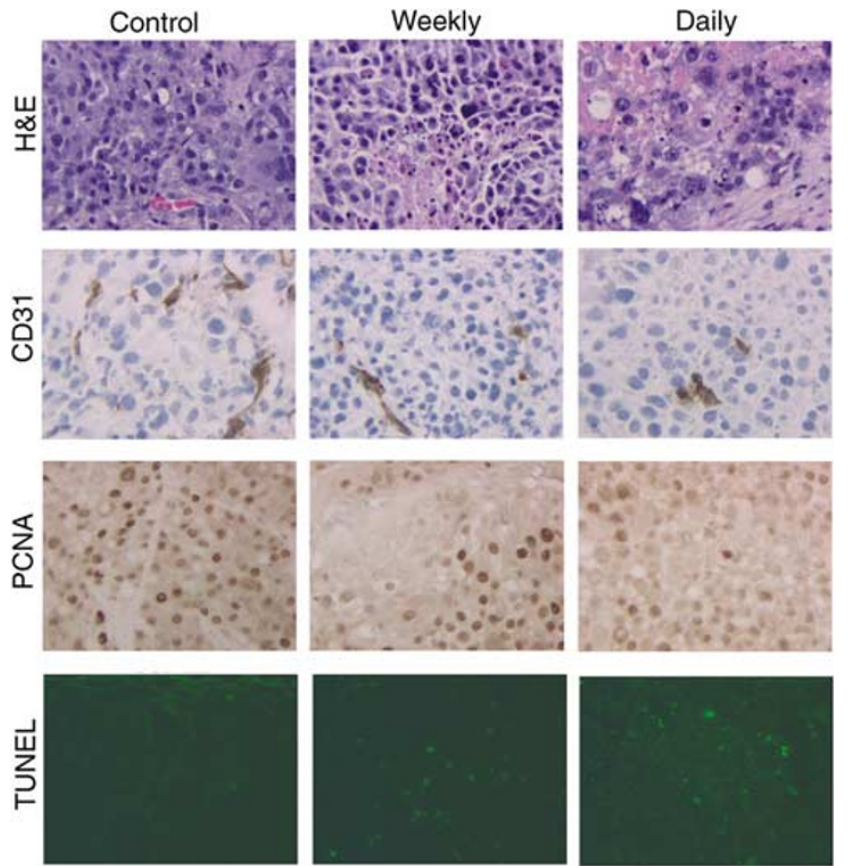

Figure 3 Immunohistochemical analysis of gastric tumours. Representative images of tumour sections stained with haematoxylin and eosin (row I $\times 200$ magnification), stained immunohistochemically for CD3I (row 2; $\times 200$ ) or for PCNA (row $3 ; \times 200$ ), or stained for apoptosis by TUNEL (row 4, $\times 200$ ). Weekly ZD6/26 caused a significant decrease in the number of PCNA + proliferating cells and an increase in TUNEL-positive apoptotic cells; daily ZD6I26 decreased microvessel density (as shown by staining with antibodies against $C D 3 \mid)$, decreased proliferating cells (PCNA) and increased apoptotic cells (TUNEL).

in the weekly group $(P<0.007)$ and 7.4 -fold increase in the daily group $(P<0.001))$.

\section{Endothelial cell apoptosis and proliferation}

Tumours harvested from mice treated with ZD6126 either weekly or daily for 38 days were stained for markers of endothelial-cell apoptosis (CD31/TUNEL), to determine whether the decrease in microvessel density was associated with increased endothelial cell apoptosis. However, at that relatively late time point, no apoptotic endothelial cells were detected (data not shown). Therefore, to examine the acute effects of ZD6126 on the tumour microvascu- lature, mice bearing established tumours were injected with a single dose of ZD6126 (100 mg/kg) on day 14, and tumours were harvested 1,3, or 5 days after the injection. As shown in Table 3, at day 1 post-ZD6126 injection, there was a significant decrease in the number of proliferating cells, as determined by the percent of BrdU-positive cells $(61 \%$ decrease $(P<0.004))$. There was also a concomitant increase in cell death at day 1 , which was sustained through to day $5(15$-fold increase at day $1(P<0.05)$ and nine-fold increase at day $5(P<0.05))$. Importantly, there was also a significant decrease in endothelial cell proliferation by day 1 post-ZD6126 injection $(56 \%$ decrease in $\mathrm{CD} 31+/ \mathrm{BrdU}+$ cells $(P<0.05))$. However, since the process of angiogenesis is determined by a balance between proliferating and apoptotic endothelial cells, the ratio of these two parameters was determined. As shown in Table 3, ZD6126 led to a significant increase in the ratio of endothelial cell apoptosis to proliferation $(57 \%: P<0.01)$. This increase was apparent as early as $24 \mathrm{~h}$ post-ZD6126 injection, and continued through day 5.

\section{DISCUSSION}

Our findings in this study demonstrate the efficacy of selectively targeting the tumour vasculature with the novel antivascular agent ZD6126 in an orthotopic model of human gastric cancer. Previous studies have described ZD6126, both as a single agent and in combination with radiation and chemotherapy, in various models in which tumour cells are implanted in subcutaneous tissues (Blakey et al, 2002; Siemann et al, 2002; Siemann \& Rojiani, 2002). Here we focus on the efficacy of single-agent ZD6126 therapy, administered in two dose schedules, in an orthotopic model of gastric cancer.

Daily dosing with ZD6126 (100 mg kg ${ }^{-1}, 5$ days per week) caused a significant inhibition of tumour growth. Once-weekly dosing, in contrast, reduced the tumour volume, but did not significantly reduce tumour mass. This difference may be due to the variability of excising and weighing the tumour, as it is difficult to ensure complete removal of the tumour, without the accompanying uninvolved stomach wall. This is reflected by the proportionately greater variability in the tumour mass measurement, especially as the tumour volume is reduced. Previous studies in subcutaneous xenograft tumour models have shown that a single bolus dose of ZD6126 produces widespread central tumour necrosis with a rim of viable tumour cells surviving treatment, which can quickly repopulate the tumour mass, resulting in limited tumour growth delay (Blakey et al, 2002). These tumour cells are not killed following drug treatment, presumably because they gain oxygen and nutrients from blood vessels in the surrounding normal tissue, which is unaffected by ZD6126 (Blakey et al, 2002). Therefore, in a rapidly growing tumour model system, repeated dosing of ZD6126 is required to obtain significant tumour growth delays (Blakey et al, 2002; Davis et al, 2002). We observe greater antitumour effects with the daily dosing schedule, which may reflect a greater opportunity for regrowth of tumour between doses of ZD6126 in the weekly schedule.

Examination of the tumour samples at the end of the experiment (day 38), $24 \mathrm{~h}$ after the last dose of ZD6126 was administered, showed that both treatment schedules produced significant antitumour effects in terms of increased tumour cell death (TUNEL-positive staining), together with decreased tumour cell proliferation (PCNA-positive staining). However, the TUNELstaining procedure can detect both apoptotic and necrotic cell death (Grasl-Kraupp et al, 1995), and, therefore, it does not clearly discriminate between these two modes of cell death. Despite that, the increase in TUNEL-positive cells is more likely due to an increase in apoptosis as areas of intense necrosis (as determined either by H\&E staining or the Hoechst counterstain) were avoided. Additionally, many of the fields that were chosen had only diffuse 


\begin{tabular}{|c|c|c|c|c|}
\hline & \multirow[b]{2}{*}{ Control } & \multicolumn{3}{|c|}{ ZD6 I 26 (100 $\left.\mathrm{mg} \mathrm{kg}^{-1}\right)$} \\
\hline & & Day I & Day 3 & Day 5 \\
\hline Tumour volume $\left(\mathrm{mm}^{3}\right)$ & $250.1 \pm 75.7$ & $242.6 \pm 31.0$ & $167.8 \pm 47.3$ & $134.2 \pm 34.6$ \\
\hline Proliferating cells \# of cells/HPF & $112.3+7.3$ & $43.7+14.7^{\mathrm{a}}$ & $78.4+14.6^{b}$ & $33.0 \pm 10.0^{\mathrm{a}}$ \\
\hline Apoptotic cells \# of cells/HPF & $0.8 \pm 0.3$ & $12.0 \pm 6.6^{\mathrm{b}}$ & $16.2 \pm 7.9^{c}$ & $7.2 \pm 3.3^{b}$ \\
\hline Microvessel density \# of vessels/HPF & $32.9+2.7$ & $29.3+2.4$ & $25.7+2.9$ & $22.8+2.6^{a}$ \\
\hline Ratio of apoptotic to proliferating ECs (\% control) & $0 . \overline{3}$ & $0.6^{c} \overline{(57 \%)}$ & $1.1^{c}(67 \%)$ & $0.8^{\mathrm{b}}(68 \%)$ \\
\hline
\end{tabular}

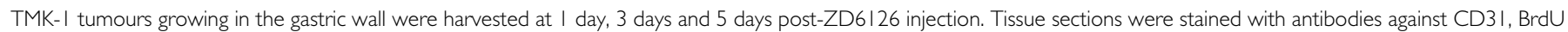

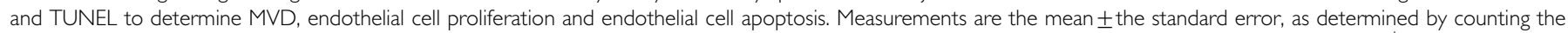

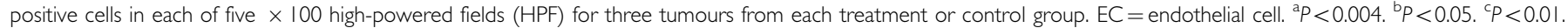

TUNEL-positive cells surrounded by areas of viable tissues, again indicative of apoptosis and not necrosis. Tumours isolated from animals following weekly or daily dosing schedules of ZD6126 appeared to have a higher degree of morphological tumour necrosis on H\&E sections (data not shown). Taken together with the increase in TUNEL staining in the tumours compared with the controls, this would be consistent with a vascular-targeting mechanism of action for ZD6126 in this anti-tumour study.

In these experiments, we did not observe increased endothelial cell death in gastric tumours examined at the end of either the daily or weekly ZD6126 treatment schedule. However, ZD6126 treatment has been shown to induce rapid occlusion of tumour blood vessels (within $6 \mathrm{~h}$ ), probably as a result of drug-induced effects on endothelial cell shape, leading to exposure of basement membrane and rapid induction of endothelial cell apoptosis and subsequent loss of vessel function (Blakey et al, 2002). Therefore, detecting endothelial cells undergoing apoptosis after multiple rounds of treatment may be very difficult, since the bulk of the potentially ZD6126-sensitive endothelial cells throughout the tumour would be affected at the earliest times of the treatment regimen. At later times, endothelial cell proliferation and vessel growth would be expected to be more localised around areas of the tumour that are nourished from nontumour vessels (e.g. at the tumour rim) which are unaffected by ZD6126 (Blakey et al, 2002).

To further investigate the dynamics of ZD6126 effects on endothelial cell apoptosis and proliferation, we treated mice bearing established tumours with a single injection of ZD6126, and harvested the tumours 1, 3 and 5 days later. Immunohistochemical analysis revealed that microvessel density tended to decrease following ZD6126 injection, reaching statistical significance on day 5 . This corresponded with a decrease in proliferating endothelial cells following ZD6126 treatment. Taken together, these observations may indicate that TMK-1 tumour regrowth and revascularisation are decoupled at early times after ZD6126 treatment, perhaps because angiogenesis is not rate limiting to tumour growth in the early-stage gastric tumours. Examination of $\mathrm{H} \& \mathrm{E}$ sections revealed that widespread necrosis was evident $1-3$ days after ZD6126 treatment. Multiple areas of focal necrosis were evident throughout the tumour mass, surrounded by regions of viable tumour tissue. By day 5 , the extent of histological tumour necrosis was reduced, as demonstrated in Figure 4 . This most likely represents tumour regrowth, as has been described in rapidly proliferating subcutaneous xenograft models (Blakey et al, 2002).

Previously, ZD6126 was shown to have significant antitumour activity in a human lung pulmonary metastasis model in nude mice (Goto et al, 2002). In this metastasis model, ZD6126 antitumour activity was associated with selective induction of apoptosis in tumour endothelial cells $24 \mathrm{~h}$ after ZD6126 treatment,

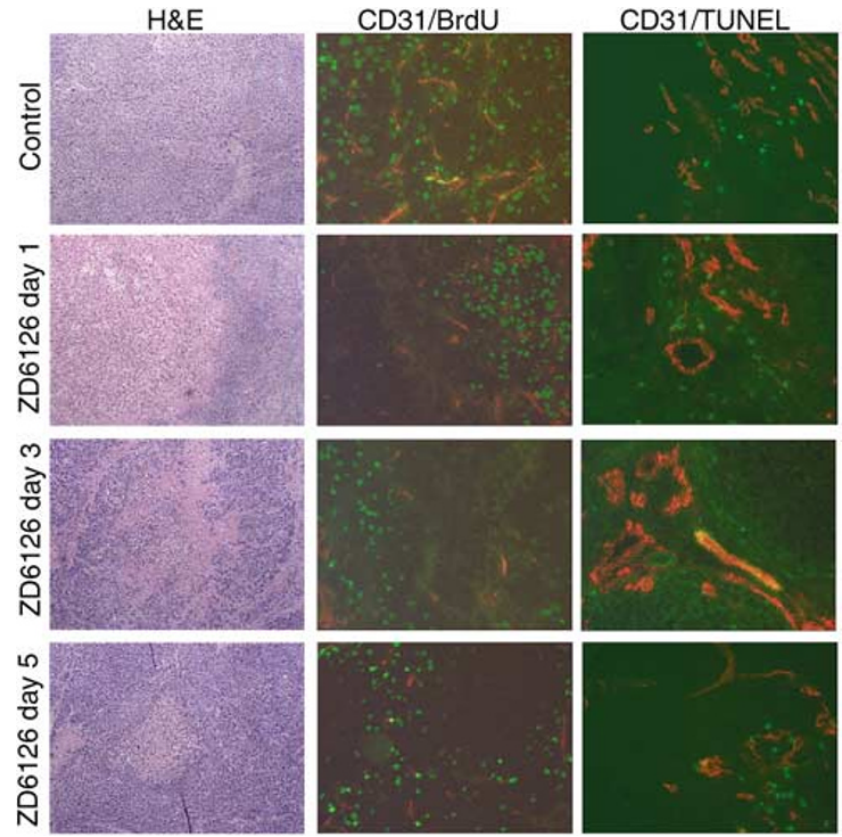

Figure 4 Immunohistochemical analysis of gastric tumours after a single dose of ZD6126. Representative images of tumour sections stained with haematoxylin and eosin (column I; $\times 40$ magnification), stained for endothelial cell proliferation by immunofluorescence for $\mathrm{CD} 3 \mathrm{I} / \mathrm{BrdU}$ (column 2; $\times 100)$ and stained for endothelial cell apoptosis by immunofluorescence against CD3I/TUNEL (column 4, × 100). A single dose of ZD6I26 caused a significant decrease in the number of dividing endothelial cells (as determined by colocalisation) and an increase in endothelial cells undergoing apoptosis, such that microvessel density was decreased by day 5 .

with associated destruction of the tumour vasculature. However, despite the widespread tumour necrosis in the lung metastases, repeated dosing was required to reduce disease burden, consistent with what has been described for other rapidly growing tumours (Blakey et al, 2002; Davis et al, 2002). In the present study, ZD6126 treatment reduced the incidence of peritoneal carcinomatosis, which may be a consequence of reducing the growth of the primary gastric tumour rather than a direct effect on the metastatic deposits in the peritoneum. In contrast to the study by Goto et al (2002), we did not see a significant increase on endothelial cell apoptosis within the tumour even at $24 \mathrm{~h}$ after ZD6126 treatment. The reason for the difference between the two studies is not 
certain, but it is possible that the apoptotic response of tumour endothelial cells to vascular-targeting agents may depend on the tumour microenvironment within each disease site. However, despite the differences in induction of tumour endothelial cell apoptosis, ZD6126 produced significant antitumour effects in both disease models.

As reported by others (Blakey et al, 2002; Goto et al, 2002), the effects of ZD6126 appear to be very selective for tumour vasculature. We did not observe any increase in cell death within the histologically normal tissues surrounding the tumour, either in epithelial or endothelial cells (data not shown).

The activity of combretastatin A-4 phosphate has been reported in several physiologically relevant mouse models, including orthotopic models of mouse (MAC 15) or human (SW620) colorectal cancer (Grosios et al, 1999), models of human colon cancer (DLD-1 and HT29) metastasis to the liver (Holwell et al, 2002) and orthotopic models of human NSCLC (KNS-62, Colo-699) (Boehle et al, 2001). In the first of these studies, a single dose of combretastatin A-4 phosphate $(100 \mathrm{mg} / \mathrm{kg})$ induced extensive haemorrhagic necrosis, with a rim of viable tumour at the periphery of the primary colorectal tumour $24 \mathrm{~h}$ after drug treatment. This effect was also observed in vascular metastatic deposits in the kidney, lymph nodes and abdominal wall, but no effect was observed in avascular deposits in the lung (Grosios et al, 1999), supporting the hypothesis that the tumour necrosis induced by the drug is secondary to vascular effects in the orthotopic setting. In the follow-up study, a single dose of combretastatin A-4 phosphate $(150 \mathrm{mg} / \mathrm{kg})$ also induced haemorrhagic necrosis in the colorectal tumours within the liver $24 \mathrm{~h}$ after drug treatment (Holwell et al, 2002). The extent of necrosis induction was significantly lower when SW620 was grown in the liver rather than as a subcutaneous tumour, indicating that the tumour microenvironment can affect the response of a tumour to vasculartargeting agents. In the final study of two human NSCLC xenografts, a daily regimen of combretastatin A-4 phosphate $\left(50 \mathrm{mg} \mathrm{kg}^{-1} \mathrm{day}^{-1}\right.$ for 21 days) significantly inhibited tumour growth in both the subcutaneous and orthotopic settings (Boehle et al, 2001).

The present study has shown that the vascular-targeting agent ZD6126 was effective in reducing the growth and peritoneal spread of human gastric cancer cells implanted orthotopically into the stomach walls of nude mice. Furthermore, the antitumour activity was improved with daily dosing compared with weekly dosing. Further studies are needed to more completely define the mechanism of action of this agent and to determine whether additional antitumour effects can be seen in this model in combination with clinically relevant chemotherapy, radiation therapy, or antiangiogenic agents. However, the present preclinical results provide support for investigating the potential activity of ZD6126 in gastric cancer in the clinic.

\section{REFERENCES}

Blakey DC, Westwood FR, Walker M, Hughes GD, Davis PD, Ashton SE, Ryan AJ (2002) Antitumor activity of the novel vascular targeting agent ZD6126 in a panel of tumor models. Clin Cancer Res 8: 1974-1983

Bloemendal HJ, Logtenberg T, Voest EE (1999) New strategies in antivascular cancer therapy. Eur J Clin Invest 29: $802-809$

Boehle AS, Sipos B, Kliche U, Kalthoff H, Dohrmann P (2001) Combretastatin A-4 prodrug inhibits growth of human non-small cell lung cancer in a murine xenotransplant model. Ann Thorac Surg 71: 1657-1665

Brown JM, Giaccia AJ (1998) The unique physiology of solid tumors: opportunities (and problems) for cancer therapy. Cancer Res 58: $1408-1416$

Bruns CJ, Liu W, Davis DW, Shaheen RM, McConkey DJ, Wilson MR, Bucana CD, Hicklin DJ, Ellis LM (2000) Vascular endothelial growth factor is an in vivo survival factor for tumor endothelium in a murine model of colorectal carcinoma liver metastases. Cancer 89: 488-499

Chaplin DJ, Hill SA (2002) Selective induction of tumor ischemia: development of vascular targeting agents for cancer therapy. Curr Opin Investig Drugs 3: $1381-1384$

Chaplin DJ, Pettit GR, Parkins CS, Hill SA (1996) Antivascular approaches to solid tumour therapy: evaluation of tubulin binding agents. $\mathrm{Br} J$ Cancer Suppl 27: S86-S88

Chi JT, Chang HY, Haraldsen G, Jahnsen FL, Troyanskaya OG, Chang DS, Wang Z, Rockson SG, van de Rijn M, Botstein D, Brown PO (2003) Endothelial cell diversity revealed by global expression profiling. Proc Natl Acad Sci USA 100: 10623-10628

Craig LE, Spelman JP, Strandberg JD, Zink MC (1998) Endothelial cells from diverse tissues exhibit differences in growth and morphology. Microvasc Res 55: $65-76$

Dark GG, Hill SA, Prise VE, Tozer GM, Pettit GR, Chaplin DJ (1997) Combretastatin A-4, an agent that displays potent and selective toxicity toward tumor vasculature. Cancer Res 57: 1829-1834

Davis PD, Dougherty GJ, Blakey DC, Galbraith SM, Tozer GM, Holder AL, Naylor MA, Nolan J, Stratford MR, Chaplin DJ, Hill SA (2002) ZD6126: a novel vascular-targeting agent that causes selective destruction of tumor vasculature. Cancer Res 62: $7247-7253$

Davis PD, Hill SA, Galbraith SM, Chaplin DJ, Naylor MA, Nolan J, Dougherty GJ (2000) ZD6126: a new agent causing selective damage of tumor vasculature. Proc Am Assoc Cancer Res 41: 329

Denekamp J (1990) Vascular attack as a therapeutic strategy for cancer. Cancer Metastasis Rev 9: 267-282

Folkman J (1992) The role of angiogenesis in tumor growth. Semin Cancer Biol 3: $65-71$
Fukumura D, Yuan F, Monsky WL, Chen Y, Jain RK (1997) Effect of host microenvironment on the microcirculation of human colon adenocarcinoma. Am J Pathol 151: 679-688

Goto H, Yano S, Zhang H, Matsumori Y, Ogawa H, Blakey DC, Sone S (2002) Activity of a new vascular targeting agent, ZD6126, in pulmonary metastases by human lung adenocarcinoma in nude mice. Cancer Res 62: $3711-3715$

Grasl-Kraupp B, Ruttkay-Nedecky B, Koudelka H, Bukowska K, Bursch W, Schulte-Hermann R (1995) In situ detection of fragmented DNA (TUNEL assay) fails to discriminate among apoptosis, necrosis, and autolytic cell death: a cautionary note. Hepatology 21: $1465-1468$

Griggs J, Metcalfe JC, Hesketh R (2001) Targeting tumour vasculature: the development of combretastatin A4. Lancet Oncol 2: $82-87$

Grosios K, Holwell SE, McGown AT, Pettit GR, Bibby MC (1999) In vivo and in vitro evaluation of combretastatin A-4 and its sodium phosphate prodrug. Br J Cancer 81: $1318-1327$

Holwell SE, Cooper PA, Thompson MJ, Pettit GR, Lippert III LW, Martin SW, Bibby MC (2002) Anti-tumor and anti-vascular effects of the novel tubulin-binding agent combretastatin A-1 phosphate. Anticancer Res 22: $3933-3940$

Jung YD, Mansfield PF, Akagi M, Takeda A, Liu W, Bucana CD, Hicklin DJ, Ellis LM (2002) Effects of combination anti-vascular endothelial growth factor receptor and anti-epidermal growth factor receptor therapies on the growth of gastric cancer in a nude mouse model. Eur J Cancer 38: $1133-1140$

Kamiyama M, Ichikawa $\mathrm{Y}$, Ishikawa $\mathrm{T}$, Chishima $\mathrm{T}$, Hasegawa $\mathrm{S}$, Hamaguchi Y, Nagashima Y, Miyagi Y, Mitsuhashi M, Hyndman D, Hoffman RM, Ohki S, Shimada H (2002) VEGF receptor antisense therapy inhibits angiogenesis and peritoneal dissemination of human gastric cancer in nude mice. Cancer Gene Ther 9: 197-201

Karpeh MS, Kelsen DP, Tepper JE (2001) Cancer of the stomach. In Cancer: Principles and Practice of Oncology, DeVita VT, Hellman S, Rosenberg SA (eds) pp 1092-1126. Philadelphia: Lippincott Williams and Wilkens

Minagawa A, Otani Y, Kubota T, Wada N, Furukawa T, Kumai K, Kameyama K, Okada Y, Fujii M, Yano M, Sato T, Ito A, Kitajima M (2001) The citrus flavonoid, nobiletin, inhibits peritoneal dissemination of human gastric carcinoma in SCID mice. Jpn J Cancer Res 92: 1322-1328

Mori A, Arii S, Furutani M, Mizumoto M, Uchida S, Furuyama H, Kondo Y, Gorrin-Rivas MJ, Furumoto K, Kaneda Y, Imamura M (2000) Soluble Flt1 gene therapy for peritoneal metastases using HVJ-cationic liposomes. Gene Therapy 7: 1027-1033 
Reinmuth N, Liu W, Fan F, Jung YD, Ahmad SA, Stoeltzing O, Bucana CD, Radinsky R, Ellis LM (2002) Blockade of insulin-like growth factor I receptor function inhibits growth and angiogenesis of colon cancer. Clin Cancer Res 8: 3259-3269

Seed L, Slaughter DP, Limarzi LR (1940) Effect of colchicine on human carcinoma. Surgery (St. Louis) 7: 696-709

Siemann DW, Rojiani AM (2002) Enhancement of radiation therapy by the novel vascular targeting agent ZD6126. Int J Radiat Oncol Biol Phys 53: $164-171$

Siemann DW, Mercer E, Lepler S, Rojiani AM (2002) Vascular targeting agents enhance chemotherapeutic agent activities in solid tumor therapy. Int J Cancer 99: 1-6

Skinner SA, Frydman GM, O'Brien PE (1995) Microvascular structure of benign and malignant tumors of the colon in humans. Dig Dis Sci 40: $373-384$
Stoeltzing O, Ahmad SA, Liu W, McCarty MF, Wey JS, Parikh AA, Fan F, Reinmuth N, Kawaguchi M, Bucana CD, Ellis LM (2003) Angiopoietin-1 inhibits vascular permeability, angiogenesis, and growth of hepatic colon cancer tumors. Cancer Res 63: 3370-3377

Thorpe PE, Chaplin DJ, Blakey DC (2003) The first international conference on vascular targeting: meeting overview. Cancer Res 63: 1144-1147

Workman P, Balmain A, Hickman JA, McNally NJ, Mitchison NA, Pierrepoint CG, Raymond R, Rowlatt C, Stephans TC, Wallace J (1998) United Kingdom Co-ordinating Committee on Cancer Research (UKCCCR) guidelines for the welfare of animals in experimental neoplasia (second edition). Br J Cancer 77: 1-10

Yoshikawa T, Yanoma S, Tsuburaya A, Kobayashi O, Sairenji M, Motohashi H, Noguchi Y (2000) Angiogenesis inhibitor, TNP-470, suppresses growth of peritoneal disseminating foci. Hepatogastroenterology 47: $298-302$ 